Universidad de Lima

Escuela de Posgrado

Maestría en Tributación y Política Fiscal

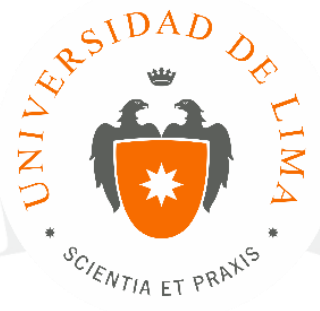

\title{
EL TRATAMIENTO TRIBUTARIO DE LOS CONSORCIOS EN LA LEGISLACIÓN DEL IMPUESTO A LA RENTA
}

Trabajo de investigación para optar el Grado Académico de Maestro en

Tributación y Política Fiscal

Victor Mejia Ninacondor

Código 20112545

Lima - Perú

Marzo de 2016 


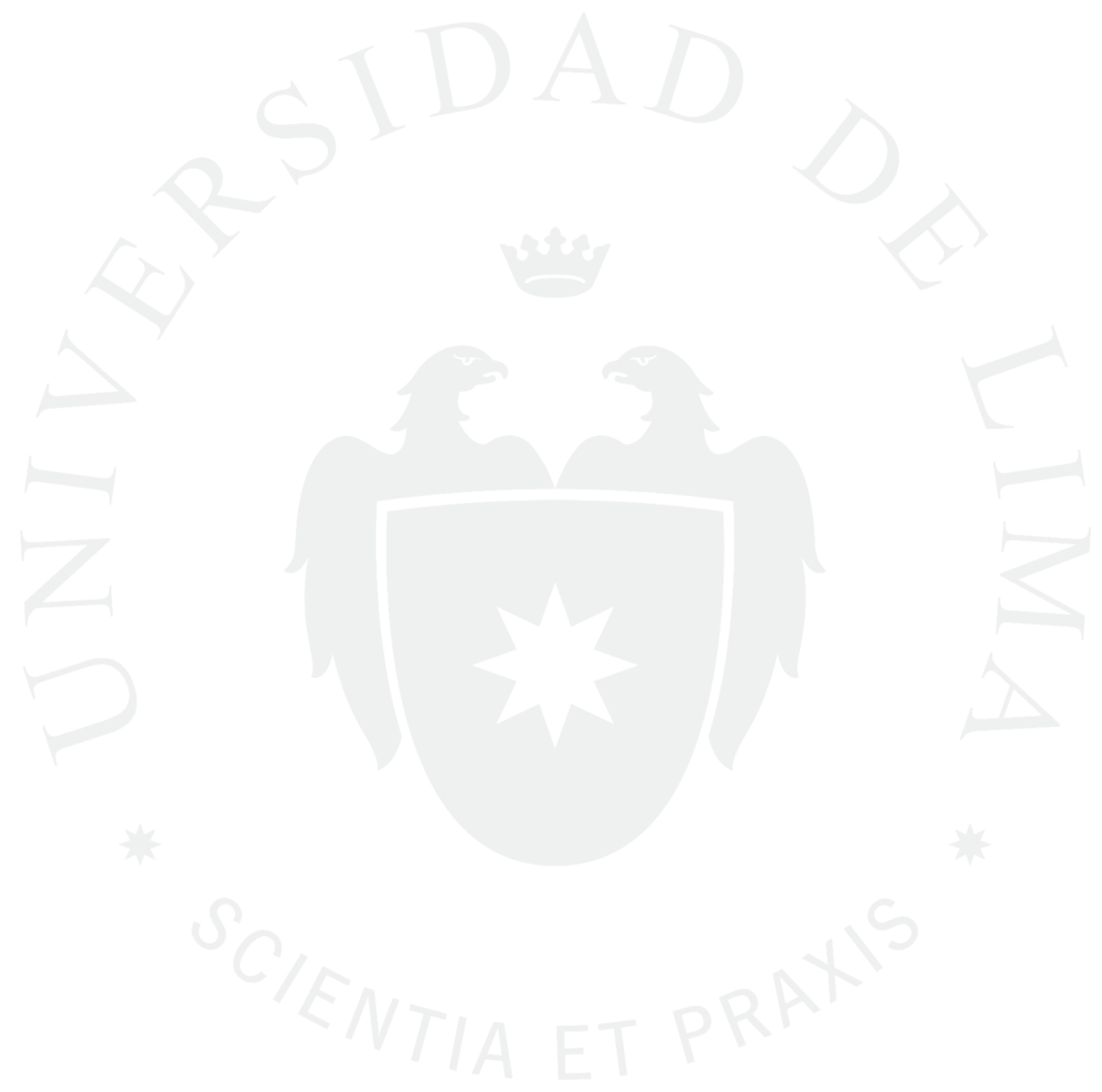




\section{EL TRATAMIENTO TRIBUTARIO DE LOS CONSORCIOS EN LA LEGISLACIÓN DEL IMPUESTO A LA RENTA}




\section{TABLA DE CONTENIDO}

CAPÍTULO I: ANTECEDENTES................................................................3

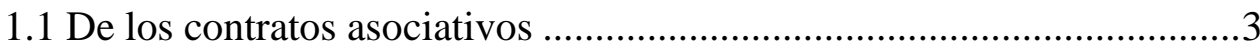

$1.2 \mathrm{El}$ joint venture y el contrato de consorcio ..........................................

1.3 Los contratos asociativos en la Ley General de Sociedades ...................8

1.4 Los contratos de consorcio y la Ley de Contrataciones del Estado ........9

CAPÍTULO II: LOS CONSORCIOS EN LA LEY GENERAL DE SOCIEDADES

11

2.1 Los contratos asociativos .............................................................11

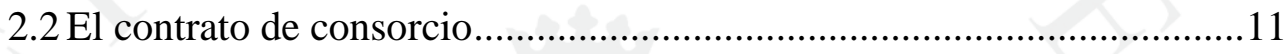

2.3 Características del contrato de consorcio............................................12

CAPÍTULO III: LOS CONSORCIOS EN LA LEGISLACIÓN DEL IMPUESTO

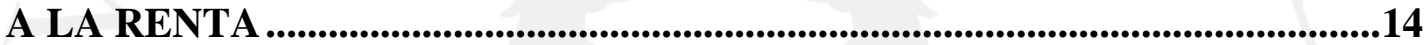

3.1. Los consorcios en la legislación del impuesto a la renta en el Perú......14

3.2. Legislación comparada ...................................................................17

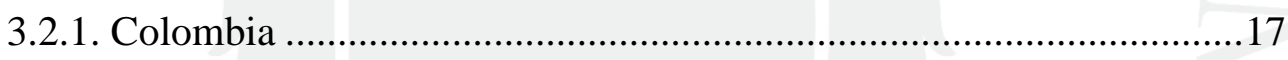

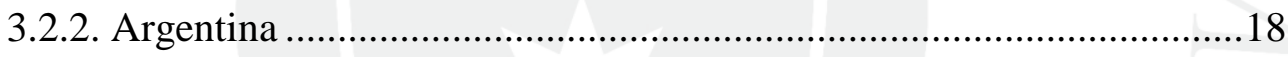

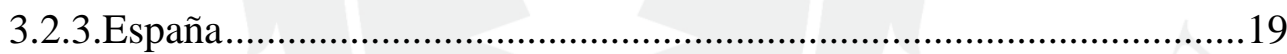

CAPÍTULO IV: ANÁLISIS DEL TRATAMIENTO TRIBUTARIO DE LOS

CONSORCIOS EN LA LEGISLACIÓN DEL IMPUESTO A LA RENTA .....20

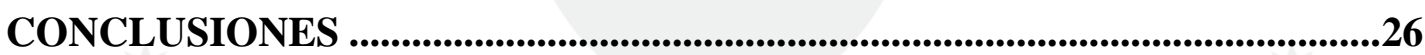

RECOMENDACIONES .....................................................................................28 


\section{INTRODUCCIÓN}

En la legislación peruana se reconocen las figuras de los contratos asociativo, algunos regulados expresamente como el contrato de asociación y participación y el contrato de consorcio, y por lo tanto son contratos nominados y típicos, y otros que si bien son reconocidos por la doctrina no tienen una regulación expresa en nuestro ordenamiento positivo como el contrato de joint venture.

Estos contratos reconocidos en la legislación civil y comercial, tienen un tratamiento particular y especial en la regulación tributaria de tal forma que si bien en el derecho común tienen una naturaleza y características determinadas, ésta es cambiada para efectos tributarios en ejercicio de la llamada autonomía del Derecho Tributario.

El presente trabajo se circunscribe al estudio del tratamiento que la legislación del impuesto a la renta en el Perú dispensa a los contratos de consorcio. Se inicia con los antecedentes que permiten ubicar al consorcio dentro del marco de los contratos asociativos detallando la evolución histórica de los mismos hasta la incorporación en nuestra legislación positiva de los contratos de consorcio.

A continuación se explica cómo nuestra regulación del impuesto a la renta vigente regular las obligaciones tributarias formales y sustanciales de los consorcios, poniendo especial énfasis, como se ha señalado anteriormente, en la naturaleza especial y particular que le asigna nuestra legislación tributaria y específicamente la legislación del impuesto a la renta.

Luego se hace un breve análisis del derecho comparado revisando el tratamiento de los consorcios y/o formas similares en las leyes que gravan las rentas en Colombia, Argentina y España. La idea en este punto es tener referencias normativas que nos permitan comprender mejor la situación tributaria de los consorcios en países con tradiciones jurídicas similares a la nuestra.

Finalmente se hace un análisis de esta regulación en la legislación peruana para manifestar nuestra opinión sobre la misma, si ésta debe ser mantenida, mejorada o modificada a la luz de su aplicación práctica en los años que ya tiene de vigencia. 
Nuestro análisis tiene un fundamente teórico y doctrinario, pero se sustenta principalmente en la aplicación práctica de las normas, es decir, no se pretende dar una opinión meramente académica sino que se busca sustentar en la casuística presentada y las ventajas o problemas que esta regulación presenta en los casos concretos que se presentan en la realidad de los sujetos de la relación jurídica tributaria.

Esperamos que este análisis sea una pequeña contribución al estudio de los consorcios en la legislación tributaria peruana. 


\section{CAPÍTULO I: ANTECEDENTES}

En el presente capítulo se hace una revisión de los antecedentes doctrinarios y normativos de los contratos asociativos hasta llegar a la regulación de los consorcios en la legislación peruana.

\subsection{De los contratos asociativos}

Según Elías Laroza (2015) el contrato de asociación en participación fue introducido en nuestra normativa societaria por los artículos 398 al 406 de la Ley General de Sociedades anterior, sin embargo, el contrato de consorcio es una innovación de la actual Ley General de Sociedades. Señala que se trata de dos contratos nominados y típicos desde que se fija no solo su denominación sino que regula detalladamente los caracteres esenciales y las normas legales aplicables a cada uno, englobando a ambos el rubro genérico "contratos asociativos".

El mismo autor señala que es interesante analizar la evolución de estos contratos en nuestra legislación, para determinar el proceso que condujo al legislador peruano a la referida clasificación. Al respecto señala que teniendo en cuenta la clasificación económica de los contratos, se suele clasificarlos en contratos de cambio, de colaboración o de cooperación, de crédito, de garantía, de conservación o custodia, de previsión, de goce, de liquidación y de disposición, como lo hace Manuel de la Puente y Lavalle. Añade que los contratos de colaboración se celebran entre personas que buscan realizar una actividad para lograr un fin concreto y que entre ellos se encuentran los “contratos asociativos", que procuran alcanzar un objeto común a todos los contratantes. Termina señalando Elias Laroza que Manuel de la Puente y Lavalle considera que en los contratos de colaboración (mandato, comisión, corretaje, edición) el fin es perseguido por uno de los contratantes, mientras que en los asociativos el fin es común a todos:

Finalidad similar [a los contratos de colaboración], tan es así que algunos autores los clasifican entre los contratos de colaboración, tienen los contratos asociativos, cuya característica es que los contratantes persiguen un fin común, como ocurre en los 
contratos de sociedad, de asociación, de sindicación de acciones, de asociación en participación. Pienso que la diferencia entre unos y otros radica en que en los primeros uno de los contratantes persigue el fin y el otro ayuda a obtener el fin querido por el primero, mientras que en los contratos asociativos el interés de los contratantes de alcanzar la finalidad común es principal para todos ellos (De la Puente y Lavalle, 1991, p. 246).

Entonces, los contratos de colaboración están orientados a un fin determinado y en la generalidad de los casos uno de los contratantes persigue el fin y el otro lo ayuda, sin embargo, en los contratos de asociación hay un interés común de los contratantes en alcanzar la finalidad que es principal para todos.

Si bien Manuel de la Puente y Lavalle no mencionan los contratos de consorcio, consideramos que les son aplicables los criterios de los contratos asociativos ya que se encuentra dentro de esa clasificación tal como señala Elias Laroza. Añade que los contratos de asociación en participación y de consorcio son el fruto de un proceso de evolución, que tiene antecedentes no siempre uniformes en nuestra legislación.

La Ley de Sociedades Mercantiles, en 1966, reguló el contrato de asociación en participación, en sus artículos 398 al 406, bajo la forma legal de un contrato nominado y típico. Tal como en la nueva Ley, se trataba de un contrato de carácter asociativo, en el cual las partes se unían para alcanzar un fin común a todos, sin dar nacimiento a una persona jurídica y sin afectar los intereses individuales de cada uno. Sin embargo, sus caracteres esenciales lo convertían en una figura contractual que no era adecuada para los casos en que todos los contratantes deseaban actuar abiertamente... (Elías Laroza, 2015, p. 696)

Por ello el propio Elias Laroza señala que con posterioridad diversas leyes sectoriales, impulsadas por las necesidades de la actividad empresarial, regularon distintas formas contractuales similares, bajo diversas denominaciones, como se detalla a continuación:

- En la legislación minera se estableció en 1991 que el titular de una actividad minera podía realizar "contratos de riesgo compartido (joint venture)" para el desarrollo de dicha actividad, éste se regulaba como un contrato asociativo que no daba lugar al nacimiento de una persona jurídica y que debía formalizarse mediante escritura pública inscrita en el registro público de minería. 
- En el sector pesquero se encuentra regulación de 1988 y 1992 sobre diversas opciones de participación transitoria de embarcaciones extranjeras pesqueras que se referían al contrato de asociación en participación y al de operaciones conjuntas de pesca (joint venture) no se especificaban requisitos aunque la Ley General de Sociedades de ese tiempo si regulaba el contrato de asociación en participación.

- En cuanto a las contrataciones y adquisiciones del Estado se encuentra que la regulación de 1997 se refiere a las ofertas en consorcio, señalando que las ofertas pueden ser realizadas por distintas personas en consorcio, con responsabilidad solidaria y apoderado común, precisando que no es una persona jurídica.

- En las disposiciones relativas a inversiones se encuentra regulación de 1991 que hace mención a inversiones a través de los contratos de asociación en participación.

\subsection{El joint venture y el contrato de consorcio}

Señala Elias Laroza (2015) que en esta diversidad legislativa vemos aparecer la referencia al joint venture que, en el derecho comparado, es un antecedente importante de los contratos asociativos. Así tanto en la anterior como en la vigente Ley General de Sociedades no se regula el joint venture, que proviene del derecho anglosajón, pues no responde a la naturaleza de los contratos asociativos que se deseaba regular en ese momento, siendo la primera gran dificultad la amplitud e imprecisión de su definición que engloba en realidad varios contratos e inclusive sociedades con personalidad jurídica. Nos remite a la definición del profesor Bradley, citado por Eduardo Chuliá Vicémt, que define al joint venture como:

Una integración de operaciones entre dos o más empresas independientes donde se encuentran las condiciones siguientes: el joint venture está sujeto al control común de las sociedades matrices, que no se hallan sujetas a un control relacionado; cada empresa matriz hace una contribución importante al joint venture; el joint venture existe como 
una empresa comercial independiente de sus sociedades matrices; y finalmente el joint venture crea una capacidad de empresa importante nueva, por lo que se trata de una nueva capacidad de producción, nueva tecnología y nuevo producto, o una nueva entrada en un mercado nuevo (Elías Laroza, 2015, p. 698)

Según Sergio Le Pera, la expresión joint adventure (o sea empresa, negocio o aventura en común), es la antecesora del joint venture. La primera se encontraba en organizaciones de gentlemen adventurers (o sea empresas, negocios o aventuras realizadas entre caballeros). Se formaron así empresas colonizadoras y, con el pasar del tiempo, la expresión fue abreviada, en lenguaje comercial, a joint venture (Elías Laroza, 2015, p. 698-699).

Elias Laroza refiere también que para Max Arias Schereiber Pezet, el contrato de riesgo compartido o joint venture es un instrumento contractual en el que las partes se juntan con un criterio de co-participación que asume diferentes formas y matices, no existe una definición exacta y final de este contrato, sino que hay varios conceptos del mismo según sean las modalidades que aparezcan en su concertación, señala además que en este contrato las partes pueden actuar de modo individual o crear una empresa que tenga personería jurídica y patrimonio propio.

Por su parte, sobre el joint venture y el contrato de consorcio, Echaiz Moreno (2012) señala:

Para algunos autores, el consorcio resulta equiparable (y hasta confundible) con la figura anglosajona del joint venture. Al respecto se comenta que "en Escocia aparece el joint venture como una respuesta abierta asociativa que aunaba la integración de recursos para un fin común, preservándose la autonomía de los sujetos asociados", señalándose entre sus principales rasgos característicos el origen contractual, la inexistencia de forma específica, la naturaleza asociativa, el derecho de los participantes a la gestión conjunta aunque independiente entre ellos y el objetivo o duración limitados. Apreciamos pues que el consorcio encajaría en las características anteriormente enumeradas, las cuales son recurrentes en la doctrina al referirse a los joint venture; así, también se ha anotado como tales la voluntad asociativa, la comunidad de intereses entre las partes, la integración de recursos por sus miembros, el mantenimiento de la autonomía operativa y jurídica de las empresas asociadas y la participación de las partes con naturaleza cooperativa en el capital de riesgo de la empresa. 
No obstante, para distinguir el consorcio del joint venture deberá considerarse la amplitud conceptual de esta última figura empresarial que la doctrina alemana define como wirtschaftlichen sachverhalt esto es, un supuesto de hecho económico ... cuya instrumentación jurídica podrá tener lugar mediante la utilización de los diferentes soportes jurídicos, tanto contractuales como societarios de los que disponga cada ordenamiento. Semejante planteamiento ofrece Jorge Silvio Sicoli cuando manifiesta que "pueden distinguirse dos tipos de joint ventures : los que se unen contractualmente y aquellos en los que se aporta capital.

Precisamente en este orden de ideas, Raúl Aníbal Etcheverry diferencia entre el joint venture contractual (non equity joint venture) y el joint venture societario (equity joint venture), siendo que el primero está dirigido normalmente a la ejecución de un proyecto limitado en el tiempo y genera relaciones puramente contractuales entre las empresas participantes, mientras que el segundo supone la existencia de una sociedad controlada conjuntamente por los participantes del negocio como si se tratase de una filial (p. 206208)

Entonces, de acuerdo a estas definiciones, el consorcio será asimilable al joint venture contractual, mas no al joint venture societario o corporativo

Siendo así el joint venture se trata de un contrato nominado pero atípico que no tiene una definición exacta, puede o no tener socios ocultos, puede tener personería jurídica o no, tiene o no un fin necesariamente común y, en general, hay varias definiciones.

Ante esta situación el legislador de la vigente Ley General de Sociedades optó por regular en forma sumamente amplia y sin limitaciones los contratos de asociación en participación y de consorcio, que son los dos contratos asociativos que abarcan la mayor parte de las necesidades de participación empresarial, dejando de lado la denominación de joint venture

De la definición legal se puede concluir que los caracteres esenciales de los contratos asociativos son:

- Tienen un fin común, de carácter principal, para todos los intervinientes.

- No dan lugar a la formación de una persona jurídica.

- Su objeto es la participación o integración en negocios o empresas determinadas. 
- Dan lugar, en nuestra Ley, a dos contratos, nominados y típicos, que son el de asociación en participación y el de consorcio.

- La Ley regula en forma amplia estos contratos, dejando un campo muy extenso a la autonomía de la voluntad privada.

- Nada impide, en nuestra opinión, que las partes celebren contratos asociativos que pueden no adecuarse a los esquemas de la asociación en participación o del consorcio, si así lo desean. Ellos serán contratos asociativos innominados y atípicos.

- La única formalidad exigible a los contratos asociativos es que consten por escrito. No es necesaria la escritura pública ni la inscripción en el registro (Elías Laroza, 2015, p. 702).

\subsection{Los contratos asociativos en la Ley General de Sociedades}

Entonces, conforme se señaló precedentemente, la anterior Ley General de Sociedades solo reguló el contrato de asociación en participación, sin embargo, esto resultó insuficiente para la amplia variedad de casos donde no se quería tener socios ocultos sino que todos los participantes del contrato deseaban ser socios activos participando abiertamente en la gestión y en las actividades del contrato. En especial este problema se presentó en el ámbito de las contrataciones del Estado donde se requería la intervención abierta y la responsabilidad de los participantes, motivo por el cual el contrato de asociación en participación no era útil para este ámbito y se fue dejando de lado reemplazándolo por un contrato atípico e innominado que frecuentemente se llamaban consorcios.

Por ello la vigente Ley General de Sociedades incorpora expresamente la regulación del consorcio por lo que pasa a ser un contrato típico y nominado en que todas las partes intervienen directamente en el negocio o empresa.

Como señala Elías Laroza (2015), nada impide que las partes decidan celebrar otro tipo de contratos distintos a los regulados en la Ley General de Sociedades que se decidan por la formación de una sociedad, pero el añadido del consorcio enriquece el universo de los contratos asociativos tipificados y regulados por la ley. 


\subsection{Los contratos de consorcio y la Ley de Contrataciones del Estado}

Tomando en cuenta que en nuestro país uno de los principales usos de los contratos de consorcio se da dentro del marco de la Ley de Contrataciones del Estado consideramos relevante hacer una breve referencia a la regulación que esta norma otorga a los consorcios.

La Ley de Contrataciones del Estado aprobada por Ley $\mathrm{N}^{\circ} 30225$ vigente desde el 09 de enero de 2016 señala en su artículo $13^{\circ}$ que:

En los procedimientos de selección pueden participar varios proveedores agrupados en consorcio con la finalidad de ejecutar el contrato ... En ningún caso, la participación en consorcio implica la obligación de crear una persona jurídica diferente.

Los integrantes del consorcio son responsables solidariamente ante la Entidad por las infracciones y consecuencias derivadas de su participación individual o conjunta durante el procedimiento de selección y la ejecución del contrato derivado de este (Ley 30225, 2014).

El numeral 4 del artículo $31^{\circ}$ del Reglamento de la Ley de Contrataciones del Estado aprobado por Decreto Supremo $N^{\circ} 350-2015-E F$ señala que uno de los contenidos mínimos de las ofertas es la promesa de consorcio legalizada, de ser el caso, en la que se consigne los integrantes, el representante común y las obligaciones a las que se compromete cada uno de los integrantes del consorcio, así como el porcentaje equivalente a dichas obligaciones (Decreto Supremo N 350-2015-EF, 2015).

Por su parte el art. $117^{\circ}$ del Reglamento de la Ley de Contrataciones del Estado señala que para perfeccionar el contrato, el postor ganador de la buena pro debe presentar, entre otros, el contrato de consorcio, de ser el caso. El artículo $118^{\circ}$ señala que el contrato de consorcio se formaliza mediante documento privado con firmas legalizadas de cada uno de los integrantes ante Notario, designándose en dicho documento al representante común. La norma precisa que no tiene eficacia frente a la Entidad contratante los actos realizados por personas distintas al representante común (Decreto Supremo No 350-2015-EF, 2015).

Finalmente, el anexo único del Reglamento de la Ley de Contrataciones del Estado define al consorcio como el contrato asociativo por el cual dos (2) o más personas se asocian, con el criterio de complementariedad de recursos, capacidades y aptitudes, para contratar con el Estado. 
Retamozo Linares (2015) señala que en cuanto a la prevalencia de las definiciones debe prevalecer la que se encuentra en el anexo del reglamento, por cuanto el Derecho Administrativo es el Derecho Común de la Administración Pública, debiendo por ello aplicarse en materia de contrataciones del Estado la definición de consorcio contenida en la norma reglamentaria, la que se sustenta en una participación complementaria amplia de los consorciados que no se restrinja necesariamente al objeto del contrato (p. 137).

Vemos entonces como la vigente Ley de Contrataciones del Estado permite y hasta promueve la conformación de consorcios para presentarse como postores, a fin de unir experiencias y requisitos que son necesarios para cumplir las condiciones establecidas, bastando con presentar una promeso formal de consorcio para ser postor.

Tal como hemos señalado uno de los principales usos de los contratos de consorcio en nuestro país se da dentro del ámbito de las contrataciones del Estado lo que trae como consecuencia que la regulación tributaria de los consorcios se aplique principalmente a quienes celebran contratos con el Estado. 


\section{CAPÍTULO II: LOS CONSORCIOS EN LA LEY GENERAL DE SOCIEDADES}

A continuación explicamos cómo se regulan los consorcios en la Ley General de Sociedades.

\subsection{Los contratos asociativos}

El libro quinto de la Ley General de Sociedades, aprobada por Ley $\mathrm{N}^{\circ} 26887$ publicada el 09 de diciembre de 1997, denominado contratos asociativos, señala que se considera contrato asociativo aquel que crea y regula relaciones de participación e integración en negocios o empresas determinadas, en interés común de los intervinientes, añade la norma que el contrato asociativo no genera una persona jurídica, debe constar por escrito y no está sujeto a inscripción en el Registro.

Queda claro entonces que por propia definición de la norma societaria el contrato asociativo no genera una persona jurídica.

Echaiz (2012) cuestiona la ubicación de la regulación de los contratos asociativos en la Ley General de Sociedades que debería estar restringida a temas obviamente societarios. Refiere que en el debate congresal de la Ley General de Sociedades vigente se abordó el tema quedando en discusión si este tema se abordaría en el Código Civil o en la Ley General de Sociedades. Finalmente, los legisladores optaron por incluir esta regulación en la Ley General de Sociedades. Sin embargo, sostiene Echaiz que atendiendo a una adecuada técnica legislativa la ubicación normativa de los contratos asociativos no correspondía a Ley General de Sociedades sino a la Ley General de la Empresa (que reemplazaría al Código de Comercio) o al Código Civil (p. 202).

\subsection{El contrato de consorcio}

Los contratos asociativos que regula la Ley General de Sociedades son de dos tipos: El contrato de asociación en participación y el contrato de consorcio. 
En cuanto a la definición del contrato de consorcio el artículo $445^{\circ}$ de la Ley General de Sociedades señala:

\begin{abstract}
Artículo 445.- Contrato de Consorcio
Es el contrato por el cual dos o más personas se asocian para participar en forma activa y directa en un determinado negocio o empresa con el propósito de obtener un beneficio económico, manteniendo cada una su propia autonomía.

Corresponde a cada miembro del consorcio realizar las actividades propias del consorcio que se le encargan y aquéllas a que se ha comprometido. Al hacerlo, debe coordinar con los otros miembros del consorcio conforme a los procedimientos y mecanismos previstos en el contrato.
\end{abstract}

En cuanto a la regulación específica del contrato de consorcio el artículo $446^{\circ}$ señala que los bienes que los integrantes del consorcio afecten al negocio conjunto, continúan siendo de propiedad exclusiva de éstos. La adquisición conjunta de determinados bienes se regula por las reglas de la copropiedad.

Asimismo, el artículo $447^{\circ}$ indica que cada miembro del consorcio se vincula individualmente con terceros en el desempeño de la actividad que le corresponde en el consorcio, adquiriendo derechos y asumiendo obligaciones y responsabilidades a título particular. Cuando el consorcio contrate con terceros, la responsabilidad será solidaria entre los miembros del consorcio sólo si así se pacta en el contrato o lo dispone la ley.

Entonces, en cuanto a la vinculación de los miembros del consorcio con terceros la regla no es la solidaridad sino que cada miembro del consorcio se vincula de manera individual con los terceros como resultado de las actividades que cada uno realiza en el consorcio. Se admite la responsabilidad solidaria de los consorciados frente a terceros solo cuando se pacta en el contrato de consorcio o cuando lo establece la ley (Elías Laroza, 2015, p. 715-716).

En cuanto a la distribución de utilidades y asunción de pérdidas la ley deja en libertad a las partes esa determinación estableciendo solo la regla supletoria de que a falta de estipulación se entiende que se produce por partes iguales (Elías Laroza, 2015, p. 716).

\title{
2.3 Características del contrato de consorcio
}


Siguiendo a Elías Laroza (2015) tenemos que las características esenciales del contrato de consorcio son:

- Es un contrato asociativo, nominado y típico.

- Regula relaciones de participación o integración en uno o más negocios o empresas que emprenden, en conjunto los consorciados, en interés común de todos ellos.

- No está sujeto a otra formalidad que la de constar por escrito.

- No origina la creación o nacimiento de una persona jurídica. Por ende, no tiene denominación social ni razón social.

- Manteniendo su autonomía, todos los consorciados participan, en forma activa y directa, en los negocios o empresas materia del consorcio. Cada miembro del consorcio debe llevar a cabo las actividades que el contrato le ha encargado o cuyo compromiso ha asumido, según el mismo instrumento.

- Cada consorciado debe coordinar su respectiva actividad con la de los demás, de acuerdo a los procedimientos y mecanismos del contrato de consorcio.

- Los bienes que se asignen a los negocios o empresas del consorcio permanecen en propiedad de cada miembro.

- Cada miembro del consorcio adquiere derechos y obligaciones, a título particular, al realizar operaciones del consorcio con terceros.

- La Ley regula los casos en que procede la responsabilidad solidaria de los miembros del consorcio frente a los terceros que contraten con este.

- El contrato establece los sistemas de participación de los miembros, en las utilidades y en las pérdidas del consorcio.

- Es un contrato sujeto a plazo, determinado o determinable. En otros términos, el plazo puede pactarse expresamente o se puede deducir del objeto del contrato.

- En general es un contrato cuyas principales cláusulas están libradas a la autonomía de la voluntad privada: por citar solamente las más importantes, mencionaremos la toma de decisiones dentro del consorcio, los poderes y actividades de cada consorciado, el régimen de distribución de utilidades y de asunción de pérdidas, el destino y propiedad de los bienes asignados, el sistema adoptado para asumir las responsabilidades entre los socios y frente a terceros y el objeto del consorcio (p. 703). 


\section{CAPÍTULO III: LOS CONSORCIOS EN LA LEGISLACIÓN DEL IMPUESTO A LA RENTA}

A continuación exponemos el tratamiento de los consorcios en la legislación del impuesto a la renta. Se hace referencia a la legislación peruana y a continuación se hace una breve reseña a la legislación comparada de Colombia, Argentina y España sobre el tema.

\subsection{Los consorcios en la legislación del impuesto a la renta en el Perú.}

La norma XI del Título Preliminar del TUO del Código Tributario señala:

\section{NORMA XI: PERSONAS SOMETIDAS AL CÓDIGO TRIBUTARIO Y DEMÁS NORMAS TRIBUTARIAS}

Las personas naturales o jurídicas, sociedades conyugales, sucesiones indivisas u otros entes colectivos, nacionales o extranjeros, domiciliados en el Perú, están sometidos al cumplimiento de las obligaciones establecidas en este Código y en las leyes y reglamentos tributarios.

También están sometidos a dichas normas, las personas naturales o jurídicas, sociedades conyugales, sucesiones indivisas $\mathrm{u}$ otros entes colectivos, nacionales $\mathrm{o}$ extranjeros no domiciliados en el Perú, sobre patrimonios, rentas, actos o contratos que están sujetos a tributación en el país. Para este efecto, deberán constituir domicilio en el país o nombrar representante con domicilio en él.

Por su parte el artículo $21^{\circ}$ del TUO del Código Tributario señala:

\section{Artículo 21.- CAPACIDAD TRIBUTARIA}

Tienen capacidad tributaria las personas naturales o jurídicas, comunidades de bienes, patrimonios, sucesiones indivisas, fideicomisos, sociedades de hecho, sociedades conyugales $\mathrm{u}$ otros entes colectivos, aunque estén limitados o carezcan de capacidad o personalidad jurídica según el derecho privado o público, siempre que la Ley le atribuya la calidad de sujetos de derechos y obligaciones tributarias. 
Entonces, según las normas señaladas, determinados entes colectivos sin personalidad jurídica pueden tener capacidad tributaria y estar sometidos al cumplimiento de las obligaciones, siempre que la Ley le atribuya la calidad de sujetos de derechos y obligaciones tributarias.

Por su parte el inciso K del artículo $14^{\circ}$ del Texto Único Ordenado de la Ley del Impuesto a la Renta señala:

Artículo 14.- Son contribuyentes del impuesto las personas naturales, las sucesiones indivisas, las asociaciones de hecho de profesionales y similares y las personas jurídicas. También se considerarán contribuyentes a las sociedades conyugales que ejercieran la opción prevista en el Artículo 16 de esta ley.

Para los efectos de esta ley, se considerarán personas jurídicas, a las siguientes:

(...)

k) Las sociedades irregulares previstas en el Artículo 423 de la Ley General de Sociedades; la comunidad de bienes; joint ventures, consorcios y otros contratos de colaboración empresarial que lleven contabilidad independiente de la de sus socios o partes contratantes [subrayado añadido].

El efecto de esta norma es que el consorcio que lleva contabilidad independiente de la de sus socios o partes contratantes es contribuyente del Impuesto a la Renta y por tanto está obligado a inscribirse en el RUC, emitir comprobantes de pago y cumplir con todas las obligaciones tributarias sustanciales y formales relacionadas a este impuesto ${ }^{1}$.

Entonces, la manera de llevar la contabilidad determina el tratamiento tributario otorgado a los consorcios. Se reconoce capacidad tributaria y la calidad de contribuyente como persona jurídica solo a los consorcios que lleven contabilidad independiente de la de sus socios o partes contratantes. Por tanto, los consorcios que no lleven contabilidad independiente, no constituyen una entidad distinta para efectos

\footnotetext{
${ }^{1} \mathrm{Al}$ respecto se debe tener en cuenta el Informe $\mathrm{N} \cdot{ }^{\circ}$ 165-2009-SUNAT/2B0000 que concluye que los consorcios que lleven contabilidad independiente de la de sus partes contratantes deben inscribirse en el RUC, conforme a lo señalado en la Resolución de Superintendencia N. ${ }^{\circ}$ 210-2004/SUNAT; y que los consorcios que no llevan contabilidad independiente están impedidos de inscribirse en el RUC, sin perjuicio que tal obligación recaiga sobre sus partes contratantes.
}

Añade que los consorcios que llevan contabilidad independiente de la de sus partes contratantes deben emitir el comprobante de pago respectivo por las operaciones que realicen; siendo que, tratándose de consorcios que no llevan contabilidad independiente y en los que cada parte contratante contabiliza sus operaciones, los sujetos obligados a emitir el comprobante de pago son, precisamente, cada una de las partes contratantes en su calidad de contribuyentes. 
tributarios y son las partes contratantes las que se consideran sujetos pasivos del impuesto.

Pero las partes que celebran un contrato de consorcio no tienen total libertad para decidir por voluntad propia si llevan contabilidad independiente de la de sus socios o partes contratantes y por ende constituir a esta entidad en sujeto pasivo del impuesto a la renta.

Así, debe tenerse en cuenta el segundo párrafo del art. $65^{\circ}$ del TUO de la Ley del Impuesto a la Renta señala:

Las sociedades irregulares previstas en el Artículo 423 de la Ley General de Sociedades; comunidad de bienes; joint ventures, consorcios y demás contratos de colaboración empresarial, perceptores de rentas de tercera categoría, deberán $\underline{\text { llevar contabilidad independiente de las de sus socios o partes contratantes }}$ [subrayado añadido].

De las normas señaladas se desprende la preferencia de nuestro legislador del impuesto a la renta por considerar a los consorcios como personas jurídicas ya que por un lado, en el artículo $14^{\circ}$, considera como personas jurídicas a los consorcios que lleven contabilidad independiente de la de sus socios o partes contratantes y por otro lado, el artículo $65^{\circ}$ señala que es obligatorio para los consorcios llevar contabilidad independiente de las de sus socios o partes contratantes.

Las excepciones para este último caso se presentan tratándose de contratos en los que por la modalidad de la operación no fuera posible llevar la contabilidad en forma independiente en cuyo caso el consorcio tiene dos opciones: la primera, es que cada parte contabilice sus operaciones y la segunda, que una de ellas lleve la contabilidad del contrato. En ambos casos se requiere la autorización de la Superintendencia Nacional de Aduanas y de Administración Tributaria quien la aprobará o denegará en un plazo no mayor a quince días hábiles, aplicando el silencio administrativo positivo. Esto está regulado en el procedimiento 47 del TUPA de la SUNAT aprobado por Resolución de Superintendencia N ${ }^{\circ}$ 192-2015/SUNAT Publicada el 17 de julio de 2015.

Adicionalmente la norma señala que tratándose de contratos con vencimiento a plazos menores a tres (3) años el consorcio tiene también dos opciones: La primera, que cada parte contratante puede contabilizar sus operaciones y la segunda, que una de ellas 
puede llevar la contabilidad del contrato. En este caso ya no es necesario solicitar autorización sino que basta con comunicarlo a la SUNAT dentro de los cinco (5) días siguientes a la fecha de celebración del contrato.

De acuerdo a lo expuesto la calidad de sujeto pasivo del impuesto a la renta de los consorcios se puede resumir de la siguiente manera:

- La regla general es que los consorcios deben llevar contabilidad independiente de la de sus socios o partes contratantes y por tanto son considerados sujetos pasivos del impuesto.

- Las excepciones son las siguientes:

- Contratos en los que por la modalidad de la operación no fuera posible llevar la contabilidad en forma independiente en cuyo caso pueden elegir si cada uno contabiliza sus operaciones o una de ellas lleve la contabilidad del contrato. Para esto requiere la autorización de la SUNAT.

- Contratos con vencimiento a plazos menores a tres (3) años en cuyo caso también pueden elegir si cada uno contabiliza sus operaciones o una de ellas lleve la contabilidad del contrato. En este caso basta con remitir una comunicación a la SUNAT.

\subsection{Legislación comparada}

A continuación se hace una breve reseña del tratamiento tributario de los consorcios y similares en las legislaciones de Colombia, Argentina y España:

\subsubsection{Colombia}

Siguiendo el trabajo de Romero Tarazona con relación al régimen tributario de los consorcios en Colombia se señala que el artículo 34 de la Ley 75 de 1986 estableció que los consorcios son contribuyentes del impuesto a la renta y los asimila a las sociedades limitadas, además, el artículo 14 dio a los consorcios la calidad de agentes de retención del impuesto. Estas normas se incorporaron al Estatuto Tributario Nacional de Colombia de 1989. 
Sin embargo, se señala que ante las dificultades prácticas y administrativas que se habían presentado al otorgar a los consorcios la calidad de contribuyentes del impuesto sobre la renta, el Congreso de la República de Colombia, en 1990, derogó dicha norma y a partir de ese momento la carga tributaria se transfirió a los miembros del consorcio de acuerdo a su participación, pero se mantuvo la calidad de agente de retención de los consorcios. En 1995 se adicionó al Estatuto Tributario el artículo 18 que expresamente establece que los consorcios no son contribuyentes del impuesto sobre la renta ${ }^{2}$.

Entonces se tiene que en Colombia, respondiendo a su naturaleza jurídica propia, los consorcios no son considerados contribuyentes de ningún impuesto, los sujetos pasivos son los partícipes que deben declarar y pagar los impuestos de acuerdo a su participación en el consorcio. Resulta particular que a pesar de no ser sujeto pasivo del impuesto la legislación colombiana ha impuesto algunas obligaciones formales a los consorcios como la de emitir factura, actuar como agentes de retención en la fuente del impuesto sobre la renta, tramitar un NIT (número de identificación tributaria) propio ante la DIAN (Dirección de Impuestos y Aduanas Nacionales) de Colombia y rendir informes a sus participes (Romero, 2002, p. 65).

\subsubsection{Argentina}

La Ley del Impuesto a las Ganancias de Argentina en su artículo primero señala que están sujetas al impuesto todas las ganancias obtenidas por personas de existencia visible o ideal. No hay mayor referencia en la norma a las uniones transitorias de empresas, como se les conoce en Argentina, ni a los consorcios. Las uniones transitorias de empresas tienen naturaleza contractual y no societaria en dicho país, de lo cual se puede desprender que para efectos tributarios estas uniones temporales no tienen la calidad de contribuyentes del impuesto sino que las sociedades que participan del agrupamiento tienen la calidad de sujeto pasivo y cada una tributa de acuerdo a su participación.

\footnotetext{
${ }^{2}$ El artículo 18 del Estatuto Tributario de la República de Colombia señala: Renta de los Consorcios y Uniones temporales (Artículo modificado por el artículo 61 de la Ley 223 de 1995) Los Consorcios y las Uniones Temporales no son contribuyentes del Impuesto sobre la Renta. Los miembros del Consorcio o la Unión Temporal, deberán llevar en su contabilidad y declarar de manera independiente, los ingresos, costos y deducciones que les correspondan, de acuerdo con su participación en los ingresos, costos y deducciones del Consorcio o Unión Temporal.
} 
Resulta importante mencionar que en Argentina las uniones transitorias de empresas si tienen calidad de sujeto pasivo para el IVA, conforme lo señala el segundo párrafo del artículo cuarto de la Ley del Impuesto al Valor Agregado que señala:

Quedan incluidos en las disposiciones de este artículo quienes, revistiendo la calidad de uniones transitorias de empresas, agrupamientos de colaboración empresaria, consorcios, asociaciones sin existencia legal como personas jurídicas, agrupamientos no societarios o cualquier otro ente individual o colectivo, se encuentren comprendidos en alguna de las situaciones previstas en el párrafo anterior (Decreto 280/97, 1997).

\subsubsection{España}

En España encontramos la Ley 18/1982 del 26 de mayo de 1982 que regula el régimen fiscal de agrupaciones y uniones temporales de empresas la cual señala en el numeral dos del artículo séptimo que la unión temporal de empresas no tendrá personalidad jurídica propia. El artículo noveno señala que los miembros de la unión temporal quedarán solidariamente obligados frente a la Administración Tributaria por las retenciones en la fuente a cuenta de los Impuestos sobre la Renta que la unión esté obligada a realizar así como por los tributos indirectos que corresponde satisfacer a dicha unión. Estas uniones deben inscribirse en un registro especial que al efecto lleva el Ministerio de Hacienda español. 


\section{CAPÍTULO IV: ANÁLISIS DEL TRATAMIENTO TRIBUTARIO DE LOS CONSORCIOS EN LA LEGISLACIÓN DEL IMPUESTO A LA RENTA}

A continuación expondremos los problemas que se generan por el tratamiento excepcional y especial que otorga la legislación del impuesto a la renta a los consorcios a fin de concluir si este tratamiento es conveniente y si se debe mantener.

Tal como hemos señalado anteriormente queda claro que para efectos no tributarios los consorcios son contratos asociativos que no tienen personería jurídica y por tanto no son sujetos de derechos y obligaciones. Sin embargo, la legislación tributaria le ha otorgado la calidad de persona jurídica para efectos del impuesto a la renta (y también para el IGV) a los consorcios que llevan contabilidad independiente a la de sus partes contratantes, siendo esto obligatorio para los consorcios salvo que se encuentren dentro de las excepciones señaladas en la norma.

Aquí encontramos el primer inconveniente conceptual ya que justamente la naturaleza jurídica y la evolución histórica de los consorcios determinan que una de sus principales características es justamente su ausencia de personería jurídica ya que quienes optan por este tipo de contrato asociativo tienen un interés común que es principal a todos los participantes y la característica de este contrato es que permite a todos los participantes ser socios activos del negocio participando abiertamente en la gestión y en las actividades del contrato. Esta característica principal de los contratos de consorcio se relativiza y hasta se desvirtúa, perdiéndose en gran medida la esencia y las ventajas que se esperaba obtener con la celebración de este contrato asociativo.

Otro aspecto a considerarse es la complejidad que se genera por el tratamiento diferenciado de los consorcios en nuestra legislación, es decir, para efectos civiles y comerciales tiene una naturaleza jurídica, sin embargo, para efectos tributarios tiene otra, pero incluso a nivel impositivo también existe un tratamiento diferenciado ya que con determinadas condiciones el consorcio será considero persona jurídica y por tanto sujeto pasivo del impuesto y de lo contrario no, con lo que cambia radicalmente la forma en que debe cumplir sus obligaciones tributarias. 
Además esta condición de sujeto pasivo tampoco se aplica a todos los tributos sino solo a las obligaciones relacionadas al impuesto a la renta y al IGV, lo cual resulta aún más complejo el sistema ya que la misma entidad tiene que actuar de dos maneras diferentes dentro del mismo ámbito tributario.

Nos queda claro que la respuesta a estas observaciones puede ir por el lado de la Autonomía del Derecho Tributario que le permite apartarse de la naturaleza jurídica que el derecho común le otorga a determinadas figuras y que no es el único caso donde se otorga la calidad de sujeto pasivo a entes sin personería jurídica, sin embargo, reiteramos aquí nuestro comentario en el sentido que en el caso particular de los consorcios esta situación altera gravemente la voluntad de quienes decidieron celebrar este contrato.

En todo caso es conveniente analizar si esta medida tributaria genera alguna ventaja, en cuyo caso se podría justificar o, por el contrario, genera más problemas que soluciones dentro del sistema tributario nacional.

Otro aspecto a considerar son los principios de la tributación óptima dentro de los cuales el principio de simplicidad tiene una relevancia singular a fin de disminuir los costos de cumplimiento y los costos de administración de los tributos. En tal sentido las medidas que hagan más complejo el cumplimiento de las obligaciones tributarias deben ser excepcionales y deberían estar justificadas por un beneficio claro y tangible de mayor trascendencia.

En el informe N. ${ }^{\circ} 050$-2014-SUNAT/4B0000 la Administración Tributaria hace un análisis del inciso K del artículo 14 del TUO de la Ley del Impuesto a la Renta y concluye que en su aplicación se debe diferenciar entre las personas jurídicas que por su naturaleza son tales de otras entidades que si bien por su naturaleza no generan una persona jurídica tienen el tratamiento de tales por las normas que regulan el Impuesto a la Renta. Entonces, aquí se añade una complejidad adicional ya que cuando hablamos de personas jurídicas para efectos del impuesto a la renta no hablamos de un concepto uniforme sino que debemos diferenciar a las personas jurídicas por su naturaleza o por su tratamiento. Más complejidad.

Al respecto es importante tener en cuenta como antecedente que mediante informe $N^{\circ}$ 207-2004-SUNAT/2B0000 la Administración Tributaria había establecido que los consorcios que llevan contabilidad independiente no gozan de la exoneración 
del IGV de la Ley de Amazonía porque no cumplen con el requisito de inscripción en las Oficinas Registrales de la Amazonía, lo cual resulta un imposible jurídico ya que los consorcios no son susceptibles de inscripción en los registros. Posteriormente mediante informe $\mathrm{N}^{\circ}$ 117-2005-SUNAT/2B0000 se dejó sin efecto este criterio, a todas luces errado, y se consideró que no es exigible este requisito para los consorcios. La importancia de la mención a este cambio de criterio es que el error se originó justamente porque a nivel tributario se otorgó a los consorcios una naturaleza que no tienen.

También se debe tener en cuenta que el informe $\mathrm{N}^{\circ}$ 196-2004-SUNAT/2B0000 establece que las operaciones que realiza el consorcio que lleva contabilidad independiente con sus partes contratantes están afectas al impuesto a la renta y a IGV, lo que por su naturaleza no debería ocurrir porque no se trata de un ente distinto, sin embargo, la ficción de la norma tributaria termina generando nuevos hechos imponibles que no existirían en caso de respectarse su naturaleza original. Además aplica el valor de marcado para estas operaciones que se realizan entre "partes vinculadas".

A nivel del Tribunal Fiscal la Resolución de Observancia Obligatoria $N^{\circ} 12591$ 5-2012 del 02 de agosto de 2012 estableció que:

Los contratos de consorcio que lleven contabilidad independiente a la de sus partes contratantes no cuentan con capacidad para ser parte en procedimientos administrativos tributarios que no están relacionados con obligaciones respecto de las que se les considera deudores tributarios.

Esto quiere decir que los consorcios que lleven contabilidad independiente a la de sus partes contratantes solo pueden intervenir en procesos relacionados al impuesto a la renta e IGV, mas no en temas relacionados con ESSALUD y ONP y, en general, en cualquier proceso distinto a renta e IGV, que son los únicos que lo consideran sujeto pasivo. Entonces el consorcio tendrá que tramitar sus procesos de una manera cuando se trata de renta e IGV y de otra en los demás casos.

Un aspecto importante a tener en cuenta es que si bien la normatividad del impuesto a la renta le otorga personería jurídica para efectos tributarios esta calificación de ninguna manera cambia su naturaleza en el derecho común, es decir, que los consorcios no tienen personería jurídica. Estando el derecho de propiedad regulado por el derecho civil es claro que en ningún caso los consorcios son sujetos de derechos y 
obligaciones en el ámbito civil, así por ejemplo los consorcios no pueden ejercer el derecho de propiedad o, lo que es lo mismo, no puede ser propietarios de nada.

Entonces, ¿cómo podemos hablar de transferencia de propiedad cuando una de las partes es un consorcio?, reiteramos que es claro que los consorcios no pueden ser propietarios de nada. Esto genera problemas cuando el hecho imponible habla de transferencias o cuando alguno de los requisitos para determinada condición es ser propietario o acreditar la propiedad de un bien.

Un hecho vinculado y no por ello menos relevante es cómo responden los consorcios por sus obligaciones tributarias, es decir, qué acciones se pueden dirigir contra el consorcio por ejemplo para cobrar la deuda tributaria impaga. Si el consorcio no es sujeto de derechos y obligaciones en el ámbito civil entonces no puede tener a su nombre inmuebles inscritos en los registros públicos, tampoco vehículos registrados en el registro de propiedad vehicular, tampoco puede ser titular de cuentas bancarias ni ser titular de derechos inmateriales. Entonces, ¿qué acción efectiva de cobranza se puede realizar contra un consorcio? Realmente las posibilidades son muy limitadas o casi nulas, muy en especial si las deudas surgen luego de haber concluido con la ejecución del negocio y el cobro de la contraprestación, como suele ocurrir.

El propio artículo $446^{\circ}$ de la Ley General de Sociedades establece expresamente, como es lógico, que los bienes que los miembros del consorcio afecten al cumplimiento de la actividad a que se han comprometido, continúan siendo de propiedad exclusiva de éstos y que la adquisición conjunta de determinados bienes se regula por las reglas de la copropiedad, se entiende entre los integrantes del consorcio. Entonces, la propia norma ratifica que los consorcios no pueden ser propietarios de nada.

Siendo así la figura del consorcio con su regulación tributaria resultaría un medio muy eficaz y legal para dejar de pagar los tributos porque simplemente no tiene bienes con qué responder por estas deudas. Es decir, la propia regulación tributaria facilita el no pago de los tributos. La Administración Tributaria queda a voluntad del consorcio que decide si paga o no paga sus tributos.

La respuesta que se podría plantear ante esta problemática es la responsabilidad solidaria pero esto también tiene sus inconvenientes como pasamos a explicar. 
Para comenzar también hemos señalado que el artículo $447^{\circ}$ de la Ley General de Sociedades establece que la regla de los consorcios en cuanta a su responsabilidad frente a terceros no es la responsabilidad solidaria sino que cada miembro asume sus propias obligaciones y responsabilidades. La excepción es la responsabilidad solidaria pero solo cuando el consorcio contrate con terceros y, además, así lo establezca el contrato o lo dispone la Ley. Como las obligaciones tributarias no tienen origen contractual sino legal, esta norma no soluciona el problema tributario.

Pero existe en el TUO del Código Tributario una norma que hace referencia a este tema, es el último párrafo del artículo $18^{\circ}$ que señala:

También son responsables solidarios, los sujetos miembros o los que fueron miembros de los entes colectivos sin personalidad jurídica por la deuda tributaria que dichos entes generen y que no hubiera sido cancelada dentro del plazo previsto por la norma legal correspondiente, o que se encuentre pendiente cuando dichos entes dejen de ser tales [subrayado añadido].

Parecería que esta norma soluciona el problema planteado pero vemos que tiene sus inconvenientes. Para comenzar la norma señala que la responsabilidad solidaria aplica con relación a la deuda que no hubiera sido cancelada dentro del plazo previsto por la Ley, entonces, siempre será necesario que transcurra el plazo previsto y que una vez vencido y no pagado se puede dar inicio a los trámites para atribuir la responsabilidad solidaria.

Aquí viene otro inconveniente y es que por principio la responsabilidad tributaria no es automática, requiere ser declarada y por tanto se debe dar inicio a un procedimiento que debe concluir con un acto administrativo que atribuya la responsabilidad solidaria el cual puede ser cuestionado y discutido en la vía contenciosa tributaria. Nada de esto sería necesario si a los consorcios no se les considerara personas jurídicas para efectos tributarios ya que por su propia naturaleza las partes contratantes responderían directamente por sus obligaciones en función a su participación.

Pero hemos dejado para el último el aspecto que consideramos más controvertido en cuanto a la responsabilidad solidaria establecido en el último párrafo del artículo $18^{\circ}$ y su relación con los consorcios. El tema es que la mencionada norma no hace referencia expresa a los consorcios sino a los entes colectivos sin personalidad jurídica y aquí surge la primera interrogante ¿podemos considerar que los consorcios 
están incluidos dentro del concepto de entes colectivos sin personería jurídica? Si justamente las normas tributarias le reconocen personería jurídica para efectos del impuesto a la renta e IGV.

Se puede llegar a la conclusión de que la norma en mención no aplica para los consorcios que llevan contabilidad independiente a la de sus partes contratantes ya que justamente por ello son consideradas personas jurídicas o, en el mejor de los casos, se puede llegar a la conclusión de que la responsabilidad solidaria solo aplica para los casos diferentes al impuesto a la renta e IGV. Está demás explicar la confusión e incertidumbre que pueden generar estas interpretaciones y la consecuencia sería que en la práctica desaparecería la posibilidad de atribuir responsabilidad solidaria a los miembros integrantes de los consorcios con las graves consecuencias que esto genera.

Por otro lado, ya ha quedado claro que la condición de persona jurídica solo aplica a temas relacionados al impuesto a la renta e IGV, pero no a otros tributos. Entonces, la pregunta es ¿cómo se cumplen las obligaciones tributarias relacionadas a otros tributos? La respuesta sería sin considerara los consorcios como personas jurídicas. No vemos justificación para este tratamiento dual a un mismo ente. Los consorcios entonces no son sujetos pasivos de los tributos relacionados, por ejemplo, a ESSALUD y ONP, y no pueden ser agentes de retención, esto hace definitivamente muy compleja la administración de estos contratos.

Por otro lado no se ven mayores ventajas de este tratamiento complejo. Quizá lo único que se logre con esto es que los ingresos y gastos del negocio se controlen en una sola contabilidad evitando traslados que puedan afectar la base imponible, sin embargo, esto mismo se puede lograr con regulaciones especiales que no hagan tan complejo el cumplimiento de las obligaciones tributarias.

Todas las empresas celebran diferentes negocios y a todos se les permite acumular sus resultados, entonces no se entiende por qué en el caso de los consorcios no se permite esa acumulación más aún si siempre aplicará el principio de causalidad. 


\section{CONCLUSIONES}

De acuerdo a la revisión de los antecedentes y al análisis del tratamiento de la legislación del impuesto a la renta sobre los consorcios, podemos concluir:

- Consideramos que el tratamiento tributario de los consorcios en la legislación del impuesto a la renta que les otorga personería jurídica a quienes llevan contabilidad independiente de la de sus partes contratantes termina desnaturalizando el contrato de consorcio ya que altera una de sus características fundamentales como es el interés común y la participación abierta y activa de las partes integrantes.

- Consideramos que esto se agrava por cuanto la legislación establece como regla general que los consorcios deben llevar contabilidad independientes de la de sus partes contratantes estableciendo solo determinadas excepciones para que esto no sea así.

- Esto ocasiona que se generen nuevos hechos imponibles donde en la realidad no los hay, ya que al crearse artificialmente un ente con personería jurídica se crea una nueva fuente de derechos y obligaciones $y$, por tanto, una nueva fuente de relaciones jurídico tributarias. Esto puede llegar a ser confiscatorio.

- Se afecta también el principio de simplicidad lo cual implica regular los costos de cumplimiento y los costos de la administración de los tributos. Con esta regulación se tiene que el consorcio tiene una naturaleza para efectos civiles y comerciales y otra para efectos tributarios. Incluso dentro del ámbito tributario hay una dicotomía porque algunos consorcios son considerados personas jurídicas y otros no, e inclusive dentro de los que se consideran personas jurídicas solo es para efectos de impuesto a la renta y IGV pero no para los demás tributos, todo lo cual hace más compleja la administración de estos entes, solo por el efecto de la regulación tributaria.

- Además de la complejidad del sistema, los problemas prácticos que hemos expuesto en el presente trabajo, originados por el mencionado tratamiento tributario, ratifican, desde nuestro punto de vista, que éste no es necesario ni conveniente para los contribuyentes ni para la Administración Tributaria. 
- Esto se hace más evidente aún cuando no se aprecian mayores ventajas por la adopción de este sistema $\mathrm{y}$, en todo caso, las pocas que pueden haber pueden obtenerse por otros medios menos complejos y que generen menos inconvenientes como el establecimientos de normas antielusivas que impidan el aprovechamiento indebido de estas figuras.

- Un ejemplo muy claro en derecho comparado se presenta en la experiencia colombiana donde inicialmente se otorga la calidad de sujeto pasivo a los consorcios pero al constatar los inconvenientes que se presentaban en la realidad se optó por eliminar este régimen de tal forma que los consorcios no son sujetos pasivos y cada partícipe está obligado a cumplir sus obligaciones tributarias de acuerdo a su participación en el negocio, estando esta última regulación vigente hasta la actualidad.

- De acuerdo a lo expuesto consideramos que se deben eliminar de la legislación del impuesto a la renta las disposiciones que otorgan la calidad de persona jurídica y por tanto de sujeto de derechos y obligaciones, a los consorcios.

- Opinamos que los partícipes de los consorcios deben tener la posibilidad de decidir si cada uno contabiliza y cumple las obligaciones de acuerdo a su participación en el negocio o que uno de ellos se haga cargo designando a un operador del contrato. Pero en ningún caso crear un tercer ente que desnaturaliza su esencia. 


\section{RECOMENDACIONES}

De acuerdo a lo expuesto a continuación detallaremos las recomendaciones que a nuestro juicio permitirían mejorar el tratamiento tributario de los consorcios en la legislación del impuesto a la renta:

- Modificación del inciso K del artículo $14^{\circ}$ y del artículo $65^{\circ}$ del TUO de la Ley del impuesto a la renta a fin de eliminar la calidad de persona jurídica y por tanto de sujeto de derechos y obligaciones, a los consorcios.

- Dejar como únicas opciones en las normas señaladas que los consorcios pueden optar por cumplir sus obligaciones tributarias en cabeza de los integrantes del consorcio, de acuerdo a su participación en el negocio o, de lo contrario, que decidan que uno de los participantes sea el operador del contrato y cumpla todas las obligaciones del contrato, dando cuenta luego a los demás participantes.

- Se debe establecer, mediante Resolución de Superintendencia, un procedimiento transitorio para que los consorcios que actualmente son personas jurídicas se adecuen al nuevo régimen otorgándoles un plazo prudencial para este fin. 


\section{REFERENCIAS}

de la Puente y Lavalle, M. (1991). El Contrato en General. Tomo I. (1ºd.). Lima: Fondo Editorial de la Pontificia Universidad Católica del Perú.

Echaiz Moreno, D. (2012). Manual Societario. Doctrina, Legislación, Jurisprudencia \& Casos Prácticos. (2 ed.). Lima: GRIJLEY.

Elías Laroza, E. (2015). Derecho Societario Peruano. La Ley General de Sociedades del Perú. Tomo II (2 ed.). Lima: Gaceta Jurídica.

Estatuto Tributario de la República de Colombia. Recuperado de: http://www.dian.gov.co/dian/15servicios.nsf/etributario?openview

Contratos de Colaboración Empresarial: Joint Ventura y Consorcio, Implicancias Tributarias (Primera Parte). (Segunda quincena junio 2008). Informativo Caballero Bustamante (641) p. A1-A5. Recuperado de http://www.google.com.pe/url?url=http://www.perucontable.com/modules/newb b/dl_attachment.php\%3Fattachid\%3D1277827302\%26post_id\%3D73341\&rct=j $\&$ frm $=1 \& q=\&$ esrc $=$ s\&sa=U\&ved=0ahUKEwjawcqmj6_LAhWEPT4KHcGrCX 8QFggTMAA\&usg=AFQjCNF1HVek6f9zT-277XlhXOqoC61iRQ

Contratos de Colaboración Empresarial: Joint Ventura y Consorcio, Implicancias Tributarias (Segunda Parte). (Primera quincena julio 2008) Informativo Caballero Bustamante (642) p. A1-A4

Le Pera (1984). Joint Venture y Sociedad. Buenos Aires: Astrea.

Ley 18/1982. Recuperado de: http://noticias.juridicas.com/base_datos/Fiscal/1181982.html

Navarro Palacios, I, Análisis Tributario de los Contratos de Asociación en Participación y Consorcio. Revista Peruana de Derecho de la Empresa. p. 89-117.

Retamozo Linares, A. (2015). Contrataciones y Adquisiciones del Estado y Normas de Control. Análisis y Comentarios. (10 ed.). Lima: Gaceta Jurídica.

Romero Tarazona, J. (2002). El Regimen Tributario Aplicable A Los Consorcios Y Uniones Temporales En Colombia (monografía para optar el título de abogado). Recuperado de: http://javeriana.edu.co/biblos/tesis/derecho/dere4/Tesis-35.pdf 


\section{PAGINAS WEB CONSULTADAS}

Administración Federal de Ingresos Públicos (AFIP) Argentina. http://www.afip.gob.ar/home/index.html

Agencia Tributaria - España

http://www.agenciatributaria.es/

Dirección de Impuestos y Aduanas Nacionales (DIAN) Colombia http://www.dian.gov.co/

Superintendencia Nacional De Aduanas Y De Administración Tributaria http://www.sunat.gob.pe/ 